\title{
Carnets
}

Revue électronique d'études françaises de l'APEF

Première Série - 5 | 2013

Métamorphoses littéraires

\section{A metamorfose em Claude Crébillon}

\section{Ana Alexandra Seabra De Carvalho}

\section{OpenEdition}

\section{Journals}

\section{Edição electrónica}

URL: http://journals.openedition.org/carnets/8279

DOI: 10.4000/carnets.8279

ISSN: 1646-7698

\section{Editora}

APEF

Edição impressa

Data de publição: 1 Maio 2013

Paginação: 77-101

\section{Refêrencia eletrónica}

Ana Alexandra Seabra De Carvalho, «A metamorfose em Claude Crébillon », Carnets [Online], Première Série - 5 | 2013, posto online no dia 23 junho 2018, consultado o 02 maio 2019. URL : http:// journals.openedition.org/carnets/8279; DOI : 10.4000/carnets.8279

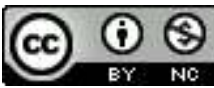

Carnets est mis à disposition selon les termes de la licence Creative Commons - Atribution - Pas d'utilisation commerciale 4.0 International. 


\title{
A METAMORFOSE EM CLAUDE CRÉBILLON
}

\author{
Ana Alexandra Seabra de Carvalho \\ Faculdade de Ciências Humanas e Sociais \\ Universidade do Algarve \\ Investigadora do CLEPUL / UALG \\ APEF \\ aacarva@ualg.pt
}

\section{Resumo}

Neste artigo, estudaremos os sentidos da metamorfose em quatro narrativas de Claude Crébillon: Le Sylphe, ou Songe de Madame de $R^{* * *}$ écrit par elle-même à Madame de $S^{* * *}$ (1730); L'Écumoire ou Tanzaï et Néadarné. Histoire japonoise (1734); Le Sopha. Conte moral (1742); e Ah Quel Conte! Conte politique et astronomique (1754). Enquanto contista, o autor recupera e transforma um vasto fundo cultural onde se cruzam as diferentes tradições associadas ao maravilhoso. Os vários sentidos da metamorfose serão aqui considerados quer enquanto processo estético-literário problematizador do exotismo maravilhoso na literatura coeva, quer como um meio lúdico e transgressor de criticar tanto a moral e os costumes excessivamente hedonistas, como as manobras do poder político. Assim, nestas obras, o processo da metamorfose está ao serviço da visão crítica sobre a literatura e a sociedade que caracteriza a poética de Crébillon.

\section{Abstract}

In this paper we will study the meanings of metamorphosis in four narratives by Claude Crébillon: Le Sylphe, ou Songe de Madame de $R^{* \star *}$ écrit par elle-même à Madame de $S^{\star * *}$ (1730); L'Écumoire ou Tanzaï et Néadarné. Histoire japonoise (1734); Le Sopha. Conte moral (1742); and Ah Quel Conte! Conte politique et astronomique (1754). As a fairy tales teller, the author gets back to and transforms a wide cultural background where different fairy-like traditions meet. Several meanings of metamorphosis will be considered here either as an aesthetic-literary process questioning fairy tales exoticism of coeval literature, either as a recreational and transgressor method to criticize excessively hedonistic morals and behaviour as well as political manoeuvres. Thus, in these works, the process of metamorphosis serves the critical vision over literature and society dear to Crébillon.

Palavras-chave: Metamorfose, Crébillon, Crítica Social e Literária

Keywords: Metamorphosis, Crébillon, Social and Literary Criticism 
Neste artigo, estudaremos os sentidos da metamorfose em quatro narrativas de Claude Crébillon: Le Sylphe, ou Songe de Madame de $\mathrm{R}^{\star * *}$ écrit par elle-même à Madame de $S^{* * *}$ (1730); L'Écumoire ou Tanzaï et Néadarné. Histoire japonoise (1734); Le Sopha. Conte moral (1742); e Ah Quel Conte! Conte politique et astronomique (1754). Enquanto contista, o autor recupera e transforma um vasto fundo cultural onde se cruzam as diferentes tradições associadas ao maravilhoso. Os vários sentidos da metamorfose serão aqui considerados quer enquanto processo estético-literário problematizador do exotismo maravilhoso na literatura coeva, quer como um meio lúdico e transgressor de criticar tanto a moral e os costumes excessivamente hedonistas, como as manobras do poder político. Assim, nestas obras, o processo da metamorfose está ao serviço da visão crítica sobre a literatura e a sociedade que caracteriza a poética de Crébillon.

De acordo com o Dictionnaire historique de la langue française ${ }^{1}$, o termo "métamorphose" (n. f.) surge, neste idioma, por volta de 1365, a partir do latim "metamorphosis" (= "mudança de forma"), transcrição do grego tardio "metamorphôsis" (derivado de "metamorphein" = "transformar-se"). O termo é atestado pela primeira vez na língua francesa no título dos poemas mitológicos de Ovídio, Les Métamorphoses, obra que contém 246 fábulas metamórficas escolhidas de entre o repertório da tradição grega e das fábulas romanas. Na mesma entrada do referido dicionário, afirma-se ainda que várias obras antigas expunham sob o mesmo título as transformações de seres humanos em animais, vegetais, fontes e objectos, tema mítico comum a todo o universo cultural indo-europeu, senão mesmo universal. Mais adiante diz-se ainda que, tendo sempre como referência o mundo antigo, o termo "métamorphose", por volta de 1493, tomou o sentido de "changement d'une forme en une autre" (Rey, 1992: 1234). No século XVII, o sentido do termo começa a expandir-se, passando a aplicar-se também

à un important changement survenant dans la fortune, le caractère de qqn. (1668) et à la transformation qu'éprouvent les substances par des causes naturelles. - En ce sens, il est passé dans la terminologie zoologique (1736) où il pourrait aussi être dérivé du verbe se métamorphoser, appliqué aux phases de la vie des insectes. [...]. / Le dérivé METAMORPHOSER v. tr. (1571) est employé lui aussi pour une transformation surnaturelle et, par analogie, au sens courant de "changer l'extérieur, le caractère de (qqn.)" (1690). - Le pronominal (1665) s'est d'abord imposé en zoologie à propos des phases de la vie des insectes et, depuis 1671, dans l'usage commun pour "changer complètement". [...]. (Rey, 1992: 1234).

Veremos adiante como Crébillon faz uso destes sentidos do termo "métamorphose".

\footnotetext{
${ }^{1}$ Cf. Rey (1992: 1234).
} 
Conhecido no seu tempo como o "físico do amor" ou o "filósofo das mulheres", Claude Prosper Jolyot de Crébillon (1707-1777) revela-se, sobretudo, como um criador rendido ao prazer da escrita e senhor de um estilo incomparável, que seduz de imediato o seu leitor e o convida à exploração profunda das suas capacidades interpretativas (cf. Carvalho, 2003). Le Sylphe, ou Songe de Madame de $R^{* \star *}$ écrit par elle-même à Madame de $S^{* * *}(1730)$ é a sua obra inaugural. Depois dela, o autor publicará as seguintes: Lettres de la Marquise de $M^{* * *}$ au Comte de $R^{* * *}$ (1732); L'Écumoire ou Tanzaï et Néadarné. Histoire japonoise (1734); Les Égarements du cœur et de l'esprit, ou Mémoires de M. de Meilcour (1736-38); Le Sopha. Conte moral (1742); La Nuit et le Moment ou les Matines de Cythère. Dialogue (1755); Le Hasard du coin du feu. Dialogue moral (1763); Les Heureux Orphelins. Histoire imitée de l'Anglais (1754); Ah Quel Conte! Conte politique et astronomique (1755); Lettres de La Duchesse de *** au Duc de *** (1768); e, finalmente, Lettres athéniennes, extraites du portefeuille d'Alcibiade (1771). De entre o corpus crébilloniano ocupar-nos-emos neste estudo das quatro narrativas que encenam elementos da esfera do maravilhoso, desenvolvendo o motivo da metamorfose, a saber: Le Sylphe, L'Écumoire, Le Sopha e a continuação deste, Ah Quel Conte!.

Le Sylphe, ou Songe de Madame de $R^{* * *}$ écrit par elle-même à Madame de $S^{* * *}$ [Paris: L. D. Delatour, 1730] (Crébillon, 1999a) surge num momento em que os elementos cabalistas e esotéricos, tais como silfos e sílfides, se encontram em voga devido ao sucesso de Le Comte de Gabalis ou entretiens sur les sciences secrètes (1670), de Montfaucon de Villars. Crébillon transforma tal moda numa reflexão sobre a libertinagem aristocrática coeva. Na sua obra inaugural, anonimamente publicada, o autor coloca em cena uma conversa jocosa travada entre um silfo libertino e uma jovem condessa, que se diz fascinada por tais entidades esotéricas. Fruto da imaginação desejante da condessa ou máscara decente para um encontro amoroso real, o colóquio versa, por um lado, sobre o imperativo da sedução e da inconstância resultante da saciedade e do desdém e, por outro, sobre a posse e a sua impossibilidade. Coloca-se, assim, a questão do desejo amoroso sob o signo do sonho, da ilusão e do devaneio, matéria que o autor explorará nas obras posteriores (cf. Carvalho, 2003).

Necessariamente breve, visto se apresentar como uma carta, e evocando um bibelot rococó pela sua graciosidade e elegância, tanto de espírito como de linguagem, Le Sylphe revela-se, porém, uma forma literária complexa pelo modo como harmoniza as convenções de alguns dos géneros narrativos predilectos no seu tempo: a epístola, o conto e o diálogo. Contudo, esta combinatória permite o jogo ambíguo entre o real e o sobrenatural, qual conto fantástico avant la lettre. Mas ela contribui, também, para a problematização das fronteiras dos géneros narrativos no contexto do seu tempo (cf. Carvalho, 2011). O título, Le Sylphe, designa um elemento maravilhoso e esotérico, ao qual parece reservado um papel de 
destaque na narrativa. O subtítulo sugere o lado ficcional da aventura ("songe"), que será, no entanto, ambiguizado pela epistológrafa, jogando entre a veracidade ou a ilusão onírica do ocorrido. Por outro lado, a formulação do subtítulo comporta ainda uma indicação genológica, isto é, trata-se de uma narrativa sob a forma epistolar aparentada com as memórias por ser constituída por uma carta singular. De acordo com as convenções em vigor, estas duas formas literárias - epistolar e memórias - decorrem de uma estética da autenticidade que se contrapõe à do conto maravilhoso sugerida pelo primeiro elemento do título. A partir da sua obra inaugural, o autor ensaia uma escrita baseada numa estética da indecidibilidade e do contraponto, da pluralidade e da problematização formais, acentuando, assim, a convenção epistolar, dado que delega em Madame de $\mathrm{R}^{\star \star \star}$ a responsabilidade da narrativa acerca do "songe" com o Silfo.

O novo modelo amoroso da libertinagem galante, florescente no seio da sociedade aristocrática francesa, representa uma verdadeira metamorfose operada na hierarquia dos valores deste microcosmo social, passando o código da galanteria a sobrepor-se ao código terno e precioso que vigorara no decurso do século XVII. Elemento imaginário cabalista, génio composto pelos mais puros átomos de ar, o Silfo de Crébillon evoca, no espírito do leitor seu contemporâneo, certas qualidades, como a juventude, a audácia, a graça e a delicadeza, que caracterizam o novo ideal de amante nascido do código do goût (valorizador do império dos sentidos sobre o dos sentimentos). A leitura do texto confirmará tais expectativas, visto que este génio aéreo e invisível aí se afirma omnisciente em relação aos mais secretos desejos e pensamentos das mulheres.

O Silfo irrompe na narrativa como uma voz que, vendo sem ser visto à maneira de um voyeur, se declara extasiado com os encantos físicos da condessa, desesperando-se quando esta os oculta. Profundo conhecedor da arte da sedução libertina, ele procura, em primeiro lugar, captar a atenção e a benevolência da mulher, despertando a sua vaidade com os elogios à sua superior beleza, indigna de um mortal. Sugere-se, assim, que a voz que fala não pertence ao plano do humano. Em seguida, a leve sugestão do desejo de posse torna-se mais explícita, embora velada ainda sob o jargão amoroso precioso: a condessa, diz a voz masculina, é uma cruel que desespera este amante respeitoso e que a adora. Ao mesmo tempo lisonjeada e curiosa, a condessa começa a vencer o medo e a surpresa iniciais, adormecendo, assim, a sua resistência. Inicia-se, então, a sua metamorfose moral, se acreditarmos na sua proclamada virtude. $O$ génio aéreo prossegue 0 jogo de sedução. Madame de $\mathrm{R}^{\star \star *}$, porém, afirma debater-se num turbilhão de ideias contraditórias, crendo, por um lado, nada dever temer desta aventura insólita e tentadora, mas, por outro, receando uma atitude violenta e atentatória da sua virtude por parte desta entidade que se diz apaixonada por si, e que ela imagina ser um espírito mais forte do que qualquer homem. Condenando severamente as falsas beatas, o libertino manifesta, no 
entanto, uma certa nostalgia da virtude sincera. Porém, segundo ele, em tempos tão conturbados pela libertinagem, a virtude mais não é que a resistência feminina aos desejos e aos caprichos dos homens, nascida da convenção social do dever do respeito pelo decoro. Quer dizer, a virtude metamorfoseou-se numa máscara que esconde o desejo, num ideal fora de moda, enquanto o prazer se mostra bem real e vivo. Se, agora, a verdadeira virtude é uma quimera e a hipocrisia condenável, então o único caminho que resta é o da aceitação da "filosofia moderna" do hedonismo e do culto da volúpia. Com base nesta argumentação falaciosa, assim como na suposta demonstração de que todos os tipos de mulher caem fatalmente nas estratégias de um mestre da sedução, o libertino tenta metamorfosear moralmente a sua interlocutora. Proclamando a vanidade da virtude feminina e contrariando toda a argumentação da condessa, sedutor e seduzida vão-se tornando progressivamente cúmplices através da sugestão de uma lei natural que, no fundo, não é mais do que o desejo do libertino.

Todavia, a condessa pretende, por um lado, resistir o máximo de tempo possível para comprovar a sua virtude e, por outro, verificar se o Silfo é, na realidade, um amante digno de si, motivos pelos quais ela procura desviar o rumo da conversa, mostrando-se curiosa em saber se o currículo das conquistas do seu interlocutor corresponde, de facto, à sua sabedoria. Aproveitando imediatamente a oportunidade que lhe é oferecida para um auto-elogio e conhecendo bem o valor da eficácia erótica de tais narrativas, a voz do Silfo libertino transforma-se, então, numa voz narradora autodiegética, que começa a contar uma parte das suas diversas aventuras amorosas. Assim, o Silfo demonstra que a sua "ciência da sedução" tem por bases a observação e a experimentação. Tal forma de pensamento, indo ao encontro do espírito racionalista da época, contrasta com a suposta natureza maravilhosa da personagem. Não obstante, a narrativa das conquistas amorosas do Silfo reforça a sua autoridade na matéria e constitui um meio táctico ao serviço da sua presente estratégia de sedução, uma vez que, por um lado, provoca na sua interlocutora a sugestão do desejo imaginado e, por outro, dá-Ihe a garantia de que, não sendo ela diferente de todas as outras mulheres, sucumbirá fatalmente, embora esteja desculpabilizada à partida. Curiosamente, verifica-se que, apesar dos seus dons, o Silfo "[a] été souvent obligé de changer de forme pour [se] faire aimer" (Crébillon, 1999a: 30): assim, para agradar a uma jovem inocente e medrosa, teve de se metamorfosear no seu professor de música; no caso de uma senhora de alta condição, porém, o Silfo bem tentou assumir a forma de um cavalheiro que a amava, mas só conseguiu os seus intentos quando se transformou num dos criados da referida dama. Outras mulheres, não acreditando que um espírito aéreo pudesse tornar-se sólido e palpável, recusaram-no (Crébillon, 1999a: 30-31). Através do processo da metamorfose, Crébillon alude aqui ao hedonismo e ao culto da volúpia reinantes no seu tempo. Após sucessivos avanços e recuos, o libertino continua a explorar a 
curiosidade e o desejo da sua interlocutora, de forma a conduzi-la na direcção que lhe é mais favorável. Por fim, diz-lhe, numa verdadeira jogada de mestre, cujo objectivo é levar a mulher a confessar o desejo e, portanto, a assumir a sua própria metamorfose moral pelo assentimento na sedução: "ne me permettez-vous donc point de me montrer?" (Crébillon, 1999a: 36-37). Madame de $\mathrm{R}^{* * *}$ procura, contudo, protelar a rendição, misturando receio e curiosidade. Seduzida pela palavra e pelo sistema do libertino, o último refúgio da condessa consiste em não lhe permitir que tome corpo. Porém, a metamorfose do Silfo não se faz esperar muito: a voz invisível mostra-se em todo o seu esplendor físico: "En ce moment une lueur extraordinaire remplit ma chambre, et je vis au chevet de mon lit le plus bel homme qu'il soit possible d'imaginer" (37). Imediatamente, qual amante terno e respeitoso, o libertino lança-se aos joelhos da condessa e suplica-lhe uma jura de fidelidade, com a qual obtém a confissão pretendida: "Oui mon cher, mon aimable Sylphe! [...], je vous jure une ardeur éternelle, je ne redoute plus que votre inconstance" (ibidem).

No final, é com toda a violência que se manifesta "l'égarement" de Madame de $\mathrm{R}^{* * *}$ ("trop de faiblesse", "mais je l'adorais!", “Ah!... Vous êtes palpable!": ibidem). Porém, apesar dos correspondentes "transports" do Silfo, trata-se de uma ocasião perdida, visto que os amantes são surpreendidos pela criada, o que provoca o desaparecimento do espírito (ou o desfazer da ilusão, ou o acordar do sonho, ou a fuga de um amante de carne e osso...). Será em vão que Madame de $\mathrm{R}^{\star \star *}$ chamará insistentemente pelo Silfo. Uma tal indiferença leva-a a considerar a hipótese de tudo não ter passado de "une agréable illusion qui s'est présentée à [s]on esprit" (ibidem). Então, decide escrever à sua confidente a dar-lhe conta desta extraordinária aventura nocturna. Termina a carta, deixando no ar uma pergunta, que tanto pode ser dirigida a si própria como à sua correspondente: "mais n'est-il pas dommage que ce ne soit qu'un songe?" (ibidem). Com esta questão, reforça-se a indecidibilidade do sentido do texto e reconduz-se ao seu início. A personagem do Silfo escondera-se na invisibilidade de uma voz tentadora e persuasiva, metonímia do desejo, sendo só perto do final que o espírito fascinador se metamorfoseia, de forma visível e palpável, no corpo do mais belo homem imaginável, numa aparição extraordinariamente ofuscante, terminando a sedução da jovem condessa, isto é, a sua metamorfose moral, que fora preparada pelo libertino ao longo de todo o diálogo. A instância autoral faz-se igualmente ouvir nas palavras finais do texto, colocadas na pena da sua personagem fictícia, dirigidas agora a todo o tipo de leitores, tanto os coevos como os das gerações subsequentes. Várias questões estão lançadas: a ambiguidade entre sonho e realidade; a (im)possibilidade de conciliação entre desejo e sentimento amoroso; a (im)possibilidade da satisfação plena do desejo. A resposta a estas questões não se encontra neste texto inaugural de Crébillon, mas elas serão retomadas, sob múltiplas formas, em todas as suas obras posteriores. Le Sylphe é, pois, desde o início, um exemplo das preocupações éticas e estéticas de Claude Crébillon. 0 
autor analisa com enorme argúcia as convenções e as modas do seu tempo, não para as imitar mas antes para as colocar ao serviço da sua visão moral e estética. Parecendo seguilas, ele está, na realidade, a contribuir para a sua profunda transformação. Assim, logo no seu primeiro texto, através de uma problematização estético-literária das regras dos códigos quer do conto maravilhoso - nomeadamente do processo da metamorfose -, quer do género epistolar, quer ainda do diálogo de sedução, Crébillon questiona o excessivo hedonismo daquilo a que chama o amour-goût, criticando o sistema da libertinagem aristocrática reinante no início do século XVIII francês.

Quatro anos mais tarde, o jovem autor dá à estampa o conto galante de suposta inspiração oriental conhecido como L'Écumoire (ou, na fórmula original, Tanzaï et Néadarné. Histoire japonoise. Paris: Prault [?], 2 vol., 1734). A carga simbólica do termo "écumoire" é aqui múltipla: erótica (o poder da virilidade, ou a sua falta por quebra do interdito sexual); político-religiosa (o poder real e a questão da Bula Unigenitus) e até literária, pois ela convida o leitor a "escumar", filtrar ou decantar a "espuma" do sentido, as subtilezas da escrita crébilloniana. Para além do objecto simbólico, surgem-nos no título duas personagens, presumivelmente um par amoroso, ideia reforçada pelo subtítulo correspondente a uma indicação genológica - Histoire japonoise. No entanto, um tal laconismo é enganador quanto à complexidade das críticas contidas neste texto, onde o amor é tudo menos simples (para além das questões sociopolíticas e religiosas). Por outro lado, do ponto de vista das convenções narrativas do tempo, a designação "histoire japonoise" encerra uma subtil contradição, se tivermos em conta que a forma "histoire" pretendia inserir-se no pólo da estética da autenticidade, narrando factos verídicos da vida $\mathrm{da}(\mathrm{s})$ personagem(ns), enquanto o adjectivo "japonoise"2 reenvia para a moda do conto maravilhoso oriental. Este jogo de oposições prenuncia aquilo que se espera no início da leitura do texto e que será reforçado no prefácio. Partindo do modelo do conto oriental fabuloso que o seu leitor aprecia devido à tradução de Galland das Mil e Uma Noites (17041717), Crébillon serve-se desta forma literária, metamorfoseando-a, para com ela envolver a sua visão crítica relativamente tanto às questões sociopolíticas, religiosas e amorosas, como também à questionação das convenções narrativas em voga, aspecto digno de relevo em todas as obras do autor.

O prefácio burlesco que antecede a história dos dois apaixonados japoneses coloca a questão da escrita literária como sucessão metamórfica de outros textos anteriores. Dividido em três capítulos (para um total de quatro páginas na edição aqui utilizada!), o seu conteúdo é resumido por Jean Sgard do seguinte modo:

\footnotetext{
${ }^{2}$ Esta "histoire japonoise", contudo, é supostamente editada "A PEKIN, Chez LOU-CHOU-CHU-LA, Seul Imprimeur de Sa Majesté Chinoise pour les langues étrangéres" (Crébillon, 1999b: 567), confusão geográfica paródica explicada (?) pelo suposto tradutor francês no prefácio.
} 
Le conte nous est donné comme la traduction tardive d'un original chinois, traduit luimême d'un texte japonais, qui provenait d'un autre texte chéchianien dont la langue même est perdue. La version chinoise a été traduite 'très imparfaitement' en hollandais, puis en latin, puis en vénitien, 'jargon difficile à entendre' pour quelqu'un qui n'a fait que deux mois d'italien. (Sgard, 1999: 263-264)

Como se pode depreender, a instância autoral leva a ficção do tradutor a uma multiplicidade de níveis tal que o resultado só pode ser a paródia hiperbólica da completa metamorfose deformante do texto original, se é que ele existiu realmente. Por outro lado, parodia-se quer a presunção dos prefácios doutos, graves e pedantes, quer a sua abolição ignorante. Assim, Jean Sgard conclui o seguinte:

Le texte est aussi conjectural que peuvent l'être l'Ancien Testament ou l'Odyssée, ouvrages hautement métaphoriques dont la valeur littérale, selon Crébillon, est perdue et dont le commentaire fait en quelque sorte tout le sens. Ce qui demeure de cet original introuvable, ce sont des mythes, des 'fables absurdes', des 'religieuses folies', des 'événements singuliers', des 'êtres imaginaires': tel est le conte de Tanzaï qui, en fait, n'est même pas une 'histoire japonaise': on est en quelque sorte à l'origine d'une fable. De quelle sorte d'histoire s'agit-il? On ne le saura guère. La féerie est ici d'une fantaisie proche de l'incohérence. (Sgard, 1999: 264)

O terceiro capítulo do prefácio acentua a acumulação paródica das traduções e dos comentários convencionados, o qual denuncia o artifício da suposta autenticidade e finge conceder ao leitor uma ampla liberdade hermenêutica, responsabilizando-o pelas suas decisões interpretativas, mas incitando-o, paradoxalmente, a buscar um sentido sério no texto: a crítica sociopolítica, moral e religiosa, velada por um feérico propositadamente excessivo, louco e absurdo.

O suposto tradutor francês, máscara óbvia da instância autoral, sublinha as sucessivas metamorfoses por que a obra foi passando ao longo dos tempos e nos diversos quadrantes geográficos por onde viajou: "on peut aisément inférer des différentes mains par lesquelles ce livre a passé, qu'il doit lui rester peu de ses grâces nationales, et je ne sais, à tout prendre, s'il en sera moins bon" (Crébillon, 1999b: 272). O pseudotradutor francês reconhece que a obra terá perdido muito do seu encanto oriental, mas, servindo-se da lítotes, mostra-se pouco preocupado com o eventual empobrecimento qualitativo da mesma daí decorrente. Em seu entender, velado e protegido pelo recurso à generalização, os leitores não terão sido prejudicados, pois os contos orientais são narrativas entediantes devido aos seus excessos extravagantes e absurdos (272-273). Porém, a generalização 
sobre os defeitos e o absurdo dos contos orientais, a qual veicula a perspectiva condenatória da poética clássica, serve ao suposto tradutor francês para preparar um elogio à sua própria criatividade. Primeiro, desvaloriza quer o texto original, quer o trabalho dos seus antecessores, embora simule uma grande seriedade crítica. Depois, elabora um panegírico hiperbolizado do seu trabalho de aperfeiçoamento do texto recebido, realizando uma tradução e adaptação ao gosto dos seus leitores, ou seja, uma nova metamorfose da obra em que o original já se perdeu há muito (273).

Depois de parodiar a moda dos contos orientais, Crébillon visa, em seguida e paradoxalmente, os autores franceses obcecados com a poética normativista e excessivamente rigorista do classicismo, herdeira dos preceitos horacianos (273-274). O pseudotradutor francês, ao mostrar-se consciente de dois motivos de aborrecimento dos leitores - a extravagância do conteúdo feérico oriental e a excessiva subserviência a uma poética rigorista francesa -, justifica-se pelo seu trabalho inventivo, elogiando sem nenhum pejo a metamorfose que terá infligido ao texto recebido. Através da denegação da autoria da obra, Crébillon valoriza-a paradoxalmente, ao elogiar o trabalho do suposto tradutor francês, a sua máscara. Nesta narrativa, a óbvia paródia dos contos orientais e da multiplicidade das sucessivas traduções, reformulações e adaptações deformantes do texto original sugere, portanto, por um lado, uma auto-irrisão e, por outro, uma estratégia defensiva contra as investidas dos críticos pedantes e/ou doutos (também eles parodiados).

L'Écumoire é, nas palavras do seu suposto tradutor francês, "une des plus extraordinaires Histoires que peut-être on se soit jamais avisé d'écrire" (Crébillon, 1999b: 437). No essencial, ela poderia ser resumida assim:

Un conte oriental de caractère féerique, déroule un cycle d'épreuves suivies de réparations. Le récit est linéaire et se déroule selon deux itinéraires inversement symétriques: le prince, frappé d'un interdit et privé de ses moyens le soir de ses noces, doit voyager et coucher avec une sorcière pour retrouver, en place de l'écumoire dont il s'est trouvé pourvu, l'organe qui lui manquait. Cependant Néadarné, privée à son tour de désirs [...], se voit contrainte de recourir à l'enchanteur Jonquille, qui lui apprendra l'amour et la rendra, apparemment vierge, à son mari. Le conte idyllique s'achève ainsi en double inconstance; le mythe de l'amour féerique aboutit à des compromis suspects; c'est le triomphe du 'désenchantement'. Sur cette toile de fond se déroule en transparence une seconde histoire, une intrigue politico-religieuse: le Prince a reçu comme tâche de faire lécher ou avaler par une vieille puis par le Grand Prêtre l'écumoire magique. II s'y efforcera d'un bout à l'autre du récit. Le lecteur de 1734 pouvait reconnaître dans la dite écumoire une figure de la Bulle Unigenitus que Louis XIV puis le Régent, à l'instigation de Clément XI, s'étaient efforcés de faire accepter au clergé. On voit donc le Patriarche, représentant du Saint-Siège, négocier 
tandis que Saugrenutio, caricature des cardinaux parisiens, résiste; on voit l'aristocratie soutenir le Roi par intérêt, et le Parlement s'opposer, par tradition, à cet excès de pouvoir, et tout s'arrange à la suite de compromis peu glorieux: au terme du récit, chacun aura oublié ses convictions et léché l'écumoire, tout comme les amants auront renié leurs serments. (Sgard, 2002: 145-146)

Esta narrativa apresenta uma dupla iniciação no amor e no "monde" (a sociedade), onde os dois príncipes deverão sofrer uma metamorfose interior, que os levará a saírem da inocência e dos preconceitos juvenis para entrarem no jogo social mundano dos adultos e dos vários poderes. Os encantamentos metamórficos sofridos por ambos, que os impedem de consumar o seu casamento de amor sem o auxílio de forças superiores, representam o interdito e a obrigatoriedade da iniciação erótica a cargo da sociedade.

Tanzaï é o primeiro a passar a prova iniciática preconizada pelo oráculo (“Qu'il aille; Qu'il parcoure; / Qu'il couche; Qu'il revienne”, Crébillon, 1999b: 310). No início da sua viagem iniciática, o príncipe encontra a Fada do Caldeirão, que o desembaraça da incómoda escumadeira substituta do membro viril desde a noite do seu casamento, o esclarece acerca do objectivo da viagem ("vous allez en bonne fortune": 312) e the fornece uma ampla provisão de uma poção mágica contra a impotência. Iludido com a promessa de uma noite maravilhosa com uma beldade feérica, o desapontamento do príncipe não poderia ser maior ao deparar com a horrenda fada Concombre (317-326). Desfeitas as ilusões, superada a violenta prova iniciática, com a ajuda do elixir e da sobreposição no seu espírito da imagem de Néadarné à da horrível fada, Tanzaï regressa a casa vexado, esgotado e decidido a manter-se fiel daí em diante. Tal experiência será por ele contada a Néadarné e ao rei sob a forma de um suposto sonho, com toda a ambiguidade que este estratagema lhe proporciona para esconder a sua vergonha relativa ao paradoxal e humilhante prazer que a aventura com Concombre afinal Ihe dera (337-338).

Curado da bizarra metamorfose que o impedia de consumar o casamento, Tanzaï vê a sua felicidade novamente perturbada. Agora é a vez de a princesa ser atingida por uma metamorfose equivalente à do marido, o que a leva, na segunda parte do conto, a partir para a ilha Jonquille em busca da cura que só o génio aí reinante lhe poderá proporcionar, como o tinha proclamado o oráculo divino, desta vez "en prose, afin qu'on l'entendît mieux": "La Princesse ne se reverra dans son premier état que le grand Génie Mange-Taupes n'en ait disposé selon sa sainte volonté" (Crébillon, 1999b: 343). O remédio anunciado aterroriza os ciúmes de Tanzaï e a virtude de Néadarné. No decorrer da sua aventura, a princesa debater-se-á continuamente entre o desejo de se curar da sua inconveniente metamorfose para agradar ao marido e a repugnância que o meio imposto para tal the causa. Ela diz preferir o sentimento platónico à dura prova que a espera. 
Crébillon, depois do Sylphe, recorre novamente à figura do sedutor maravilhoso, superior aos demais e irresistível, mesmo para a sincera, virtuosa e apaixonada Néadarné. O génio Jonquille é um libertino cínico, cujo desejo não se satisfaz pela posse de uma vítima enganada, mas sim pelo prazer que the proporciona o jogo agonístico da sedução persuasiva, aquela que leva a vítima a confessar o seu desejo e, portanto, a participar na sua própria derrota e humilhação. Moustache, uma fada metamorfoseada em toupeira para fugir à vingança do génio e que surge como adjuvante dos desafortunados príncipes, apresenta-Ihes Jonquille como um poderoso génio "à système", que, para o reforçar, "se fonde d'abord sur ce que les femmes à sentiments l'ont toujours trompé, en lui donnant moins de plaisir que celles qui ne se livrent à lui que par besoin, ou par sensualité effective" (367). Jonquille considera ainda que seria loucura privar-se, "pour un seul objet, de tous ceux qui pourraient plaire" (367-368). Este sistema do prazer, vigente na sociedade galante, escandaliza os jovens esposos, sinceramente apaixonados, apesar da "bonne fortune" de Tanzaï. Contudo, a inocência de Néadarné sairá também ela metamorfoseada graças aos sofismas de Moustache e de Jonquille, embora o seu amor pelo marido permaneça constante, como se diz no final (cf. p. 436). Com efeito, o início da metamorfose moral de Néadarné deve-se a Moustache, cujo discurso preparatório para o que se passará no rito iniciático é determinante para o sucesso persuasivo do génio sedutor:

Qu'est-ce qui fait le crime? C'est le consentement. Ce n'est pas vous qui vous souhaitez entre les bras de Jonquille, donc vous ne pouvez pas être criminelle. Vous ne désirez seulement pas de recouvrer votre première forme, ce n'est que par rapport à votre époux que vous la regrettez, et si vous vous soumettez à ce qui peut vous la rendre, ce n'est que pour lui; par conséquent, il ne peut que vous en estimer davantage de lui avoir sacrifié vos répugnances. (Crébillon, 1999b: 373)

Tanzaï, embora mortificado, decide-se finalmente a deixar partir a princesa para a sua prova iniciática. Para isso contribui bastante outra metamorfose física (secretamente provocada por Moustache) de Néadarné, que, à aproximação do local do sacrifício, se torna cada vez mais feia e decrépita, podendo mesmo rivalizar com a horrível fada Concombre. $\mathrm{O}$ príncipe deseja agora que a esposa recupere integralmente o seu estado inicial e a sua beleza e torna-se menos implicativo. Para tranquilizar Néadarné, Moustache revela-lhe ainda, numa conversa a sós, alguns segredos preciosos. Em primeiro lugar, ensina-lhe a pronunciar três palavras mágicas que produzem um efeito metamórfico, constituindo "un remède excellent pour réparer les outrages que nous font les emportements des hommes" (Crébillon, 1999b: 375). Depois, revela-lhe a falsidade do "sonho" da cura de Tanzaï (376). Por fim, persuade-a de que, na verdade, Jonquille é extremamente "aimable" e "charmant" 
(377). Uma vez mais, a fada argumenta que o sentimento é um preconceito errado e que a natureza sempre o apaga, ainda que por breves instantes (377-378), afirmando ainda que a necessidade que a princesa tem de passar a noite do seu desencantamento com o génio exclui o amor (379). Contudo, mesmo na posse de todas estas revelações, a angústia de Néadarné persiste no momento de ir ao encontro do "sacrificador" que operará a sua metamorfose física, correspondente, na verdade, a uma metamorfose moral, que a iniciará nas novas regras mundanas e eróticas.

Jonquille, ao desejar o desejo de Néadarné (e não o seu amor), procura persuadi-la a aceitar de livre vontade a sua infidelidade ao marido amado e, portanto, as máximas do sistema galante. É neste sentido que o génio vai conduzir a sedução, sempre evitando, maliciosamente, exercer a força do coup d'autorité (violação) e mostrando-se delicado e cortês, criando na sua ilha um locus amoenus erótico capaz de deslumbrar a jovem, provido de festejos, banquetes, canto, dança, jogos, ópera, fogo-de-artifício, etc. Cortês, mas fazendo uso da sua autoridade, o libertino demonstra à neófita que o rito iniciático é uma necessidade; que o sentimento é uma quimera ou uma hipocrisia; que o início da sedução começa pela aceitação da expressão linguística inequívoca do desejo; que o consentimento dela é imprescindível. Néadarné inquieta-se com a ternura excessiva que Jonquille lhe mostra e, sobretudo, com as dúvidas que começam a assaltá-la. Contudo, a virtude da princesa não facilita a tarefa do libertino. Tal facto faz intervir a fada Concombre, metamorfoseada numa enorme aranha que se introduz sob o vestido de Néadarné. O susto e o desmaio consequente proporcionam ao génio um momento de conquista (o terceiro), mas que, como os anteriores, falha. A princesa afasta-se, indignada. Contudo, Jonquille conseguirá persuadi-la.

Assim, a ingenuidade inicial de Néadarné, que acreditava no amor e na moralidade ideais, sofre a influência do sistema galante e começa a metamorfosear-se. Sentimentos e sentidos podem não ser indissociáveis; a natureza revela-se rebelde à vontade e à razão. Porém, o livre arbítrio, dando oportunidade de escolha - ceder ou resistir à tentação -, não apaga o remorso (fruto, talvez, de preconceitos). O génio vai agir agora em dois registos diferentes mas complementares: ao nível discursivo e ao nível da retórica não-verbal (gerindo a distância entre si e a princesa, tocando-a, beijando-a, tomando "les plus grandes libertés", até concretizar a metamorfose curativa). Jonquille afirma-se apaixonado, respeitoso e merecedor da complacência da princesa, enquanto se aproxima dela ("en s'asseyant sur le canapé" - p. 413). Em seguida, queixa-se da indiferença dela e, "en posant doucement sa main sur la jambe de la Princesse" (ibidem), considerando-se indigno de uma recompensa, adverte-a, porém, de que, na eventualidade de ela se arrepender futuramente de permanecer encantada, terá de ser outro génio a valer-lhe na sua necessária metamorfose. Aqui, sempre em silêncio, Néadarné parece começar a ceder: olha-o, desvia o 
olhar, suspira com tristeza. Jonquille continua a ganhar terreno, avançando sobre o canapé, pegando-Ihe na mão e prosseguindo com o seu discurso tranquilizador e persuasivo. $O$ primeiro efeito obtido é o facto de Néadarné lhe apertar a mão em sinal de assentimento, o que leva o sedutor a insistir "assez indiscrètement" nas suas carícias. A "profonde rêverie" de Néadarné facilita-Ihe a ousadia, ao ponto de ele conseguir beijá-la com ardor e, em seguida, tomar as maiores liberdades. Saída da sua "distraction", a princesa debate-se contra os avanços do sedutor, mas sem sucesso. Apesar da sua resistência, o génio, favorecido pelo desmaio, consegue libertá-la do encantamento que a atormentava: "Jonquille, le victorieux Jonquille, loin de la secourir, goûtait à loisir les charmes de son triomphe" (414). Contudo, esta "cura" da primeira metamorfose sofrida corresponde, na verdade, ao triunfo de uma metamorfose de tipo moral operada sobre os preconceitos da jovem virgem, pois o desencantamento metamórfico só é eficaz se for voluntário e se a vítima se convencer de que o sentimento é uma quimera, entregando-se ao império do desejo. Com efeito, o desejo vence a virtude e o escrúpulo moral, embora não por completo. Néadarné não é uma coquete hipócrita, o seu dilema interior é sincero, mas a natureza sobrepõe-se por momentos ao amor e à virtude. Ela necessita, antes de mais, de se autojustificar para tranquilizar os seus escrúpulos: serve-se, então, do mesmo subterfúgio utilizado por Tanzaï, ou seja, ela procura ver no amante a imagem do príncipe amado. Quando esta ilusão deixa de surtir efeito, e a razão volta a ganhar terreno, Néadarné tenta refugiar-se na desculpa de que a sua cedência à tentação do desejo se deveu exclusivamente ao seu amor pelo marido e aos interesses do reino. É também em nome dos interesses e da vaidade de Tanzaï que a princesa decide testar o segredo de Moustache que lhe permite regressar intacta, mas curada, aos braços do marido. Fica satisfeita com o resultado, mas é assaltada por uma dúvida: e se o segredo fosse válido apenas uma vez, apesar das promessas da fada? Segunda experiência, novos motivos de contentamento para ela e, sobretudo, para Jonquille. Vemos, assim, afirmar-se, subtil e maliciosamente, a vitória do prazer dos sentidos sob o véu do interesse do sentimento amoroso: a iniciação ao mundo das máscaras, mais ou menos hipócritas, está concretizada, ou seja, a metamorfose moral da jovem inocente que advém da metamorfose do desencantamento.

No momento em que Néadarné se prepara para partir, o génio procura obter dela o consentimento para novos encontros, o que ela recusa, tentando refugiar-se nos argumentos de sempre: o amor por Tanzaï, o dever, a fatalidade divina e política que determinou a necessidade da queda iniciática mas que interdita novas ocasiões (Crébillon, 1999b: 420). Porém, tal tentativa de autodesculpabilização é inútil: o libertino não se desvia do seu projecto de sedução cínica - depois de ter obtido os favores de Néadarné, ele insiste em fazê-la confessar a sua aquiescência e o seu desejo, tornando-a cúmplice da sua própria 
sedução e, portanto, impossibilitando-a de procurar refúgio nas desculpas por ela invocadas. Então, o libertino revela o seu verdadeiro poder, dizendo:

Quand je vous ai demandé cette permission, Princesse, reprit-il, c'est parce que jusques au bout j'ai voulu vous devoir tous mes plaisirs. Si vous connaissiez bien ma puissance, vous ne douteriez pas que, malgré tous vos refus, je ne pusse vous voir quand je le voudrais, et obtenir même de votre tendresse toutes les faveurs que vous réservez à Tanzaï. Maître de prendre sa figure, c'est sous ses traits que vous me verrez et vous ne saurez jamais si c'est à lui ou à moi que vous livrerez votre cœur. (Crébillon, 1999b: 420; itálicos nossos)

Metamorfoseada física e moralmente, Néadarné vê o seu "suplício" tornar-se perene com a ameaça final do génio de assumir a seu bel-prazer a forma de Tanzaï no leito conjugal. Conclusão: sob a máscara do amor (e/ou da hipocrisia) encontra-se sempre a necessidade do desejo sensual. Os sentidos dominam o ser, mesmo quando apaixonado; portanto, é inútil tentar resistir ao seu poder. Aquelas palavras do génio libertino, terrivelmente proféticas, são de imediato confirmadas por um novo ataque. Néadarné não resiste, movida agora pelo desejo de satisfazer o pedido de Moustache e obter a libertação do amante da fada, Cormoran. A malícia deste alegado pretexto é acentuada pelo facto de a princesa recorrer de novo ao segredo da fada para, com mais facilidade, "provoquer le Génie au sommeil" (420). Quando o consegue, decide partir. Porém, a beleza do "aimable Génie" e a recordação dos momentos de prazer passados na sua companhia deixam-na perturbada e "avec une peine dont elle sentit murmurer sa vertu" (421). A sua aventura veio provar que a natureza tolda o sentimento. Também Jonquille se metamorfoseou aos olhos da princesa: de sacrificador temido e odiado, transformou-se em "le plus aimable des génies" e em libertador: "Ce n'était pas qu'elle l'aimât, mais elle n'avait rien à lui imputer de ce qui s'était passé entre eux, et ne pouvait raisonnablement le regarder que comme son libérateur" (423).

Apesar de o seu amor por Tanzaï não se ter modificado, a metamorfose moral da princesa leva-a a considerar agora que o coração e os sentidos são independentes. Contudo, ela precisa também de preservar a sua "gloire" e a sua "tranquillité" (431) para se assegurar do amor e da estima do príncipe, assim como da sociedade. Desta forma, encontra-se na necessidade de mentir, contando a sua aventura como se fosse um sonho (430) e servindo-se do segredo de Moustache. Pequena vingança, talvez, da aventura pretensamente onírica de Tanzaï. A moral da história, segundo a perspectiva de Crébillon, é a de que, num mundo dominado pela galanteria, a sobrevivência depende da aceitação das convenções sociais. Neste sentido, um casamento de amor como o de Tanzaï e Néadarné 
comporta, como afirma Colette Cazenobe, "un dosage subtil de sage dissimulation et de nécessaire mauvaise foi" (Cazenobe, 1991: 123-124). O jogo feérico das metamorfoses físicas e morais por que passam os jovens esposos neste conto galante de perfume oriental serve para levar o leitor francês de Setecentos a reflectir sobre os códigos de conduta, tanto na intimidade, como em sociedade e na política. Serve igualmente para questionar as complexas relações, caras a Crébillon, entre "le cœur", "l'esprit" e "les sens". Por fim, este jogo das metamorfoses está também profundamente associado à transformação dos códigos narrativos coevos que constitui um traço dominante da poética crébilloniana, como se pode constatar a partir do exemplo do Sopha, que trataremos em seguida.

Le Sopha. Conte mora ${ }^{\beta}$, obra publicada em 1742, embora redigida muito provavelmente por volta de 1736-7, ou seja, apenas dois/três anos após a publicação de L'Écumoire, é, sem dúvida, um dos textos mais emblemáticos de Claude Crébillon. Aproveitando a moda do conto oriental decorrente do sucesso da versão de Galland das Mil e Uma Noites, o autor metamorfoseia-a, uma vez mais de acordo com os seus fins. O conto teria sido supostamente publicado no ano "de l'Hégire M.C.XX", em "Gaznah, de l'Imprimerie du Très-Pieux, Très-Clément et Très-Auguste Sultan des Indes" (Crébillon, 2000: 735). Ora, este sultão é apresentado como sendo o neto de Schéhérazade e do sultão das Mil e Uma Noites. O perfume exótico e sensual corresponde, assim, a um artifício delicado para a crítica dos costumes coevos. Tão delicadamente frágil, aliás, que o poder se vê na obrigação de condenar um autor reincidente - que já havia sido preso por causa de L'Écumoire - a três meses de exílio.

Trata-se, então, de um conto moral, na verdade, uma recolha de conversas apresentadas por um narrador intradiegético, Amanzei, presentemente um cortesão do sultão das Índias, mas que, no passado, teria visto a sua alma condenada a errar de sofá em sofá (!) até que dois amantes virgens a libertassem daquela punição conferida por Brama devido à sua libertinagem. A extravagância desta metempsicose ${ }^{4}$, motivo tradicional do conto maravilhoso oriental, é usada por Crébillon para valorizar a estrutura da narrativa libertina. Para tal, o autor adapta-a aos seus fins, conjugando-a com o topos do voyeurismo, dado que Amanzei se recorda de tudo o que presenciou e é capaz de o narrar ao mais ínfimo pormenor. A narração da sua desventura mostra que a personagem fútil se metamorfoseou interiormente pela observação dos desregramentos amorosos, mas também de alguns bons exemplos, dos seus contemporâneos, o que leva à reflexão moral. O

\footnotetext{
${ }^{3}$ Cf. Crébillon (1742). Le Sopha. Conte moral. "A Gaznah, de l'Imprimerie du Três-Pieux, Três-Clément \& TrêsAuguste Sultan des Indes, L'An de l'Hégire M.C.XX. Avec Privilège du susdit". [Prault], 2 vol.

${ }^{4}$ É a seguinte a origem do termo em francês: "MÉTEMPSYCHOSE n. f. a été emprunté (1562) au bas latin metempsychosis, calque du grec tardif (IIle s. après J.-C.) metempsukhôsis 'passage d'une âme d'un corps dans un autre', formé de meta ( $\rightarrow$ méta-) et de empsuchôsis 'action d'animer', dérivé de psukhê 'âme' ( $\rightarrow$ psyché). Aux XVIle et XVIIle s., il est écrit métempsychose. [...] / Le mot designe la doctrine de la transmigration des âmes. Par métonymie, le pluriel se rapporte aux incarnations successives d'une âme après la mort. [...]" (Rey, 1992: 1234).
} 
maravilhoso da metempsicose, que aqui podemos considerar um caso especial da metamorfose (cf. Jean-François Perrin, 2002; Raymonde Robert, 2002), constitui um pretexto para a análise da casuística amorosa preciosa, servida pela subtileza refinada das perífrases que caracterizam o estilo "entortillé", tanto de Amanzei como de Crébillon.

Este conto, verdadeiramente moral não obstante as sugestões eróticas contidas no título Le Sopha, deve, então, ser lido como uma obra relativa aos costumes (mores), sua observação e análise. Com efeito, Agra mais não é que o reflexo da dissoluta capital francesa que o leitor contemporâneo de Crébillon bem conhece, e que o seu duplo Amanzeisofá descreve assim:

Ici, l'on se rendait par vanité; là, le caprice, l'intérêt, l'habitude, même l'indolence étaient les seuls motifs des faiblesses dont on me faisait le témoin. Je rencontrais assez souvent ce mouvement vif et passager que l'on honore du nom de goût, mais je ne retrouvais nulle part cet amour, cette délicatesse, cette tendre volupté qui, chez Phénime, avaient fait si longtemps mon admiration et mes plaisirs. [...] Quelles mœurs! [...] Non, Brama qui les connaît, m'a flatté d'une espérance vaine; il n'a pas cru qu'avec ce goût effréné des plaisirs qui règne dans Agra, et ce mépris des principes qui y est si généralement répandu, je pusse jamais trouver deux personnes, telles qu'il les demande, pour m'appeler à une autre vie. (Crébillon, 2000: 331)

Por um lado, é compreensível o desespero de Amanzei, cuja alma se vê condenada a transmigrar sucessivamente de sofá em sofá. Contudo, o facto de ele ter finalmente recuperado a sua forma humana é um sinal de esperança do ponto de vista moral.

A "Introduction" do Sopha, extensível à sua continuação Ah Quel Conte!, consiste num prefácio autoral mascarado, verdadeira abertura da narrativa pela voz de um locutor anónimo que se dirige a um alocutário também ele anónimo e colectivo. O tom utilizado joga com o equívoco entre a crítica de costumes de tom mais realista e a ficção feérica conhecida:

II y a déjà quelques siècles qu'un prince nommé Schah-Baham régnait sur les Indes. II était petit-fils de ce magnanime Schah-Riar, de qui l'on a lu les grandes actions dans Les Mille et une nuits; et qui, entre autres choses, se plaisait tant à étrangler des femmes, et à entendre des Contes: celui-là même qui ne fit grâce à l'incomparable Schéhérazade, qu'en faveur de toutes les belles histoires qu'elle savait. (Crébillon, 2000: 281; itálicos nossos)

O leitor contemporâneo de Crébillon julga, assim, ter entrado no universo fabuloso dos contos orientais, pois sabe bem que Schah-Baham não é uma figura histórica, mas o 
neto de duas personagens ficcionais perdidas na noite dos tempos, o Schah-Riar e a Schéhérazade das Mil e Uma Noites. No entanto, a admiração pela narrativa citada é, desde logo, problematizada pela ironia apreciativa das personagens: as "grandes actions" do "magnanime Schah-Riar" parecem resumir-se, afinal, ao prazer de "étrangler des femmes" e "entendre des Contes" (Crébillon, 2000: 281), facto este que o levou a poupar a "incomparable Schéhérazade" devido às suas belas histórias. Schah-Baham é apresentado, em seguida, como um sultão pouco perspicaz e também ele apaixonado pelos contos da sua avó, possível alegoria de uma literatura "antiga" e caduca: "On assure même que le Recueil des Contes de Schéhérazade, que son auguste grand-père avait fait écrire en lettres d'or, était le seul livre qu'il eût jamais daigné lire" (282). Em contraponto, a sultana possui um espírito arguto, sendo a sua inteligência apresentada como uma qualidade rara num meio tão frívolo, espelho da corte de Luís XV (284). A sultana, por sua vez, critica os contos maravilhosos com tal veemência, que se institui no texto um contraponto irónico em relação à apologia anterior:

En effet, s'écria la Sultane, il en faut beaucoup pour faire des contes! Ne dirait-on pas, à vous entendre, qu'un Conte est le chef-d'œuvre de l'esprit humain? Et cependant, quoi de plus puéril, de plus absurde? Qu'est-ce qu'un ouvrage (s'il est vrai toutefois qu'un Conte mérite de porter ce nom), qu'est-ce, dis-je, qu'un ouvrage où la vraisemblance est toujours violée, et où les idées reçues sont perpétuellement renversées; qui, s'appuyant sur un faux et frivole merveilleux, n'emploie des êtres extraordinaires, et la toute-puissance de la Féerie, ne bouleverse l'ordre de la Nature, et celui des Éléments, que pour créer des objets ridicules, singulièrement imaginés, mais qui souvent n'ont rien qui rachète l'extravagance de leur création? Trop heureux encore si ces misérables fables ne gâtaient que l'esprit, et n'allaient point par des peintures trop vives, et qui blessent la pudeur, porter jusques au cœur des impressions dangereuses? (Crébillon, 2000: 286)

A argumentação da sultana funda-se nas críticas à inverosimilhança e à imoralidade dos contos, e do romance em geral, veiculadas pelos teorizadores literários e pelos moralistas. Este contraponto é um dos traços mais significativos da poética crébilloniana, que joga, assim, com discursos contraditórios, simulando dar uma liberdade de escolha ao leitor e colocar sob suspeita a sua própria obra, mas apenas, estrategicamente, para melhor a valorizar enquanto critica os preconceitos estéticos e morais contra o romance. Ao longo das duas narrativas em que participam como auditores-comentadores Schah-Baham e a sultana (Sopha e Ah Quel Conte!), assistiremos, aliás, à inversão destas posições de ataque e de defesa dos contos maravilhosos por parte de ambos. Schah-Baham, que os defendia com o argumento do prazer, mostrar-se-á constantemente entediado com os diálogos das 
personagens e os comentários dos dois narradores, Amanzei (Sopha) e Moslem (AQC). A sultana, por seu turno, atacando os contos em geral como vimos, apreciará o modo de narrar de Amanzei, mostrando-se amiúde sua cúmplice, como a instância autoral desejaria que o fosse o seu leitor astuto, o que prova o cómico desorientador da "Introduction". Contudo, para com Moslem ela é bastante mais severa nas suas críticas (Crébillon, 2001: 408). Desta forma, Crébillon pode assumir uma posição distanciada e problematizar a própria razão de ser de tal discussão, chamando a atenção para o papel do leitor, o de primeiro nível, apenas interessado na história; e o de segundo nível, apreciador sobretudo do modo de contar, isto é, do fazer literário.

Relativamente ao Sopha, a questão da inverosimilhança do maravilhoso resume-se às metamorfoses sofridas por Amanzei, necessárias, contudo, para que ele possa testemunhar a intimidade dos habitantes de Agra, de modo a narrar as diversas aventuras libertinas, galantes ou amorosas. Seguidor do bramanismo, que crê na metempsicose, Amanzei vê a sua alma condenada a habitar vários sofás, como castigo dos desregramentos das suas vidas passadas, como homem e como mulher, até que "deux personnes se [donnent] mutuellement, et sur [lui], leurs prémices" - Crébillon, 2000: 293). A sua punição é suavizada pelo facto de poder transportar-se de sofá em sofá, segundo os seus desejos (ibidem). O gosto pela variedade, a análise dos ridículos e a capacidade de penetrar, imperceptível, na intimidade secreta dos parceiros dos jogos de sedução fazem de Amanzei o duplo de Crébillon e do seu cúmplice leitor. Este narrador de $2^{\circ}$ grau guardou a memória das suas vidas passadas - facto raro, justificado pela singularidade da punição (e por necessidades estéticas de verosimilhança...). Isso permite-lhe condensar em si próprio os principais traços caracterizadores do desregramento geral: enquanto mulher, constata a fatalidade das máscaras e dos equívocos - galante na juventude, hipócrita na maturidade, torna-se prude e morre no meio dos prazeres secretos; enquanto homem, a imagem do petit-maître é o reflexo da anterior (Crébillon, 2000: 291). Ambos os sexos são ridicularizados. Mas a memória do passado permite-lhe também expor os costumes, utilizando uma estrutura narrativa em forma de leque, ou seja, através de variações à temática amorosa. Na busca do sentimento verdadeiro, comum a Amanzei-sofá e a Crébillon-romancista, esta narrativa apresenta-nos uma amostra representativa das variedades contrastantes da sedução. O espectro vai desde a depravação mais hipócrita e brutal até ao amor mais sincero. Contudo, este não é um sentimento descorporalizado (como Amanzei descobrirá ${ }^{5}$ ); a maior virtude é a sinceridade no amor, envolvendo a totalidade do ser. O contraponto é a libertinagem movida pela vaidade, hipocrisia e

\footnotetext{
${ }^{5}$ Amanzei apaixona-se por Zéînis quando a sua alma não possui um corpo masculino. O seu desespero provoca a reacção do sultão: "de quoi vous avisiez-vous de devenir amoureux pendant que vous n'aviez pas de corps? Cela était d'une folie inconcevable, car, en bonne foi, à quoi cette fantaisie pouvait-elle vous mener?" (Crébillon, 2000: 455) - tant pis para o platonismo...
} 
depravação mascarada. São estes os exemplos a contrario prevalecentes no Sopha. Os dois últimos capítulos, contudo, põem em cena a jovem Zéïnis, tão perfeita que desperta a paixão da alma de Amanzei, e o seu apaixonado Phéléas. Estes dois amantes satisfazem, enfim, as condições prescritas por Brama para a libertação da alma de Amanzei, o que the provoca, contudo, um misto de felicidade e desespero ao ver-se livre e de novo metamorfoseado em ser humano, mas devido à felicidade de outro e afastado do objecto dos seus desejos. Esta mistura de satisfação e decepção complexifica ainda a estética do contraponto crébilloniana, cuja estrutura fizera alternar vício e virtude, levando a que a narrativa termine aparentemente sob a égide da última - o amor sincero, correspondido e unindo sentimento e desejo -, mas à custa do sofrimento de outrem. A libertação de Amanzei e a consequente assunção da forma humana são condições indispensáveis para a existência de tal narrativa, fazendo com que o sobrenatural e o realismo das cenas eróticas surjam entrelaçados, permitindo a análise psicológica e de costumes, tanto mais que a condição imposta para a libertação redentora de Amanzei tardara em produzir-se. Enquanto moralista, Crébillon, como nota Carmen Ramirez, "ne renoncera pas à incorporer la peinture des mœurs à une vaste enquête intellectuelle, modulée par le dialogue, le scepticisme et l'ironie" (Ramirez, 2002: 228). De facto, continua a autora, "au triple palier poétique, intellectuel et heuristique, [il], conçoit le soupçon du merveilleux comme le besoin nécessaire de comprendre les mécanismes de l'esprit humain, trop enclin à l'illusion, et de maîtriser les clés morales et historiques de la société, trop asservie à l'imposture" (ibidem). Assim, também o Sopha, erradamente condenado por imoralismo, se lido de forma mais profunda, revela que o maravilhoso e o motivo metamorfose (aqui sob a forma especial da metempsicose) devem ser considerados como meios lúdicos e transgressores de criticar e problematizar tanto a moral e os costumes excessivamente hedonistas, como as manobras do poder político e religioso, estando ao serviço da visão crítica sobre a literatura e a sociedade que caracteriza a poética de Crébillon.

Cerca de uma década após a publicação do Sopha, Crébillon dá à estampa um novo "conto oriental", que pode ser considerado como a continuação do anterior - Ah Quel Conte! Conte politique et astronomique ("A Bruxelles, chez les frères Vasse, 8 parties, et une Romance, 1754"). Aliás, a sua génese é bastante complexa, com uma duração de composição que se estende provavelmente entre 1736, isto é, a época de produção do Sopha, e 1754 (cf. Jomand-Baudry, 2001 e 2002). O título parece desconcertante, uma vez que a exclamação, por um lado, sugere o carácter fabuloso dos contos numa perspectiva depreciativa e, por outro, prepara o leitor para a bizarra narrativa metamórfica atribuída ao 
Vizir Moslem 6 . Por contraponto, o subtítulo, ao indicar o género do conto, adjectiva-o de "politique et astronomique", ou seja, parece conferir-Ihe uma certa seriedade, na linha dos contos filosóficos também em voga no século XVIII (cf. Ramirez, 2002). A provocação ao leitor é clara, e a expectativa deste não será defraudada.

A narrativa inicia-se com as aventuras e desventuras amorosas de Schézaddin e da fada Tout-ou-rien, alegorias prováveis do jovem Luís XV e de Mme de Mailly, o que evidencia a crítica política e social. Como sintetiza Régine Jomand-Baudry:

[S]éduit par les rêves enchanteurs dirigés par la fée Tout-ou-rien, le jeune roi indifférent s'éveille à l'amour, mais il est bientôt détrompé sur la véritable origine de ce coup de foudre qu'il attribuait au destin: l'idylle se clôt par une rupture et une malédiction de la fée [...]. [S]'ouvre ensuite une seconde époque marquée par un deuxième coup de foudre du roi pour une jeune princesse-oie qu'il rencontre dans une cour enchantée [...]. Au cours de cette seconde époque, deux personnages deviennent narrateurs de leur propre vie: le roi Autruche, père de la jeune oie prénommée Manzaïde, retrace ses aventures et sa défaite contre le génie Plus-vertque-Pré qui, en guise de punition, l'a métamorphosé, lui et sa cour, en volatiles [...]. [P]arallèlement, la reine des îles de Cristal narre au favori du roi, Taciturne, sa vie de libertine manquée et ses espérances d'échapper un jour à la malédiction qui la condamne à une frustration sexuelle éternelle [...]. [L]e conte devient un conte à épreuves, puisque le désenchantement de l'oie et de toute la basse-cour est conditionné par le mariage de celle-ci avec un jeune roi. Mais [...] le texte se perd dans un inachèvement problématique. [...] [O]n note cependant [...] la présence d'une situation-cadre au sein de laquelle l'histoire est narrée par un vizir à deux auditeurs: le sultan Schah-Baham et la sultane-reine. (Jomand-Baudry, 2001: 277-278)

A fada Tout-ou-rien é detentora dos convencionados poderes sobrenaturais, aos quais se associa o fascínio da libertina. Recorre, então, a eles para operar a metamorfose sentimental de Schézaddin, provocando-Ihe um coup de foudre pela sua pessoa. Por este meio, ela desperta os sentidos adormecidos do jovem rei e inicia-o no amor. Tal como em L'Écumoire, a iniciação amorosa está a cargo de uma sociedade libertina. Porém, o jovem rei descobre que o coup de foudre não fora obra do destino, como era suposto, e rompe violentamente com a fada. Esta condena-o, então, ao rídiculo coup de foudre por uma princesa metamorfoseada em gansa, devido a um encantamento que afectara o rei seu pai e toda a corte. Trata-se do Roi des Terres vertes, grande físico, mas que o génio Plus-vert-

\footnotetext{
${ }^{6}$ Recorde-se o início do Sopha, quando o Vizir (é verosímil que se trate de Moslem) afirma: "Sire [...], je puis assurer Votre Majesté, que non seulement j'en sais [des contes], mais que j'ai même le talent d'en faire de si bizarres, que ceux de feu Madame votre grand-mère n'ont rien qui les puisse surpasser" (Crébillon, 2000: 286).
} 
que-Pré derrotara e metamorfoseara em avestruz. A metamorfose do rei e da corte em vários tipos de aves de capoeira parodia a ingenuidade e/ou a tolice dos cortesãos ${ }^{7}$.

Segundo a arenga política de Quamobrem, "le Grand Raisonneur", existem alguns pontos fundamentais a reter relativamente à estranha história do Roi Autruche:

Ce Roi, vaincu par une Tête à Perruque (ayez, je vous prie, la bonté de suivre ceci), dépouillé tout à la fois, par les malheurs de la guerre, de son plat à barbe [qu'il chérissait plus que sa vie, et qui lui venant en droiture du Destin a acquis pour prix de ses services, le précieux don de prophécie] et de ses États, pris même dans une ratière, est encore, pour comble de maux, transformé en Autruche par son adversaire, Génie comme lui, ainsi que vous le voyez, mais beaucoup plus puissant [...]; et que non seulement lui, la Reine sa femme et toute sa Cour sont Autruches: mais encore que cette punition s'étend sur Mademoiselle sa fille, qui est Oison, sur son propre neveu [...], dont on a fait un Dindon; sur sa cousine, Princesse d'un rare mérite, qui, pour cela, n'en est pas moins Grue, et sur tous leurs sujets [...]. Mais ce qui va, sans doute, vous faire trembler pour eux, c'est que ce Roi, sa femme, sa fille, ses parents, ses peuples doivent rester sous ces formes ridicules, jusques à ce qu'il se trouve un Prince qui prenne assez de goût pour l'infortunée Princesse, dont on a fait une Oie, pour consentir à l'épouser [....]. (Crébillon, 2001: 608)

O auditório de Quamobrem reage de forma indignada perante tal conto qualificado como o mais "ridicule", “déplacé", "impertinent", "inepte", "fade”, "indécent”, "absurde”, etc. jamais inventado (609-610). Porém, a questão é mais delicada quando se aplicam as "chaves" interpretativas, que se referem à guerra da Sucessão da Polónia, à humilhação do rei Estanislau I Leszczyński e, pior ainda, ao bizarro casamento da filha deste com Luís XV daí a pertinência no título do adjectivo "politique" para designar este conto absurdo. Quanto ao adjectivo "astronomique", ele relaciona parodicamente o conto com o rei polaco, que passava por ser um entusiasta das novas disciplinas científicas, mas também constitui um piscar de olhos ao leitor mais arguto e amante do conto filosófico. Assim, este texto satiriza o discurso científico, confrontando maravilhoso e ciência. Por outro lado, ele parodia ainda tanto os topoï do romance sentimental e de cavalaria (relação amorosa entre Schézaddin e

\footnotetext{
7 "[I]l ne s'agissait, sous couvert du conte le plus farfelu, que de faire le récit des amours de Louis XV, de son mariage inattendu avec la polonaise Marie Leszczynska, et des inénarrables aventures du roi Stanislas, son père. Deux fois élu roi de Pologne et deux fois dépossédé de son trône, ce dernier avait été installé duc en viager de la terre de Lorraine par la France en 1737. Ses déboires et ses prétentions politiques toujours déçues en avaient fait la risée d'une partie de l'Europe. Crébillon le représente sous la figure d'une autruche. II raconte aussi l'histoire d'une mystérieuse reine des Îles de Cristal, cousine du roi Autruche et partageant sa disgrâce. Cette souveraine déchue d'un bien fragile royaume se rapproche, par certains traits, de la duchesse du Maine, dont les prétentions politiques s'étaient effondrées avec l'échec de la conspiration de Cellamare, et qui avait dû se contenter de continuer à régner sur la cour de Sceaux, travestie en grande prêtresse de l'ordre de la Mouche à miel, et d'être élue reine d'un jour des fêtes nocturnes qui animaient ces lieux enchantés. Jusqu'à sa mort, en 1753, son pouvoir n'excédera pas les limites de son salon. Un roi d'opérette pouvait, en bonne fiction, s'allier à une reine de cartonpâte" (Jomand-Baudry, 2001: 276-277).
} 
Tout-ou-rien; a cena do coup de foudre por uma gansa e o auto-retrato de Manzaïde; uma cena de escuta indiscreta; o combate singular travado entre dois perus, etc.), como os do conto maravilhoso (riquezas hiperbólicas, metamorfoses, amores monstruosos) ${ }^{8}$.

Trata-se de uma narrativa profundamente experimentalista que parte da tradição para a metamorfosear. Crébillon combina aqui, com grande mestria, os sucessivos encaixes narrativos; a problematização dos géneros literários, onde se misturam tradições e formas de escrita (cf. Jomand-Baudry, 2002); e, ainda, várias mises en abyme paródicas (a diegese é recontada quatro ou cinco vezes sob diversas formas: narração de Moslem, confidência mal intencionada de Taciturne, discurso político de Quamobrem, romança e versos de Taciturne). Desta forma, Crébillon questiona constantemente os próprios limites textuais e a sua metamorfose criativa. Assim, seguindo o esquema narrativo das Mil e Uma Noites e considerando Ah Quel Conte! a continuação do Sopha, temos, num 1ํ nível narrativo, um narrador heterodiegético, máscara da instância autoral, responsável pela "Introduction" ao Sopha e que coloca em cena três personagens de cada vez, intervindo para comentar a sua inter-relação: o sultão e a sultana, auditores e comentadores dos contos fabulosos de Amanzei e de Moslem. Estes tornam-se, então, narradores intradiegéticos (num 2ํㅡível) homodiegético, no caso de Amanzei, que testemunhara, metamorfoseado em sofás diversos, as histórias que conta; heterodiegético, no caso de Moslem. Num $3^{\text {o }}$ nível, hipodiegético, as personagens dos contos de ambos os narradores contam a sua própria história: Zulica, no Sopha; o Roi Autruche e a Reine des Îles de Cristal, em Ah Quel Conte!. Trata-se de narradores autodiegéticos, também eles constantemente interrompidos pelos seus respectivos interlocutores (Nassès; Schézaddin; Taciturne). Contudo, em Ah Quel Conte!, a complexificação narrativa agudiza-se com a incorporação de cartas entre Schézaddin e Manzaïde; peças de oratória política; uma romança (“Pont-Neuf”), que constitui, como vimos, uma das mises en abyme paródicas de toda a narrativa, assim como uns "beaux couplets" sobre a paixão do príncipe Schézaddin por uma princesa metamorfoseada em gansa, peças poéticas da autoria do favorito Taciturne... Como nota Régine Jomand-Baudry, a instância autoral

joue de plus en plus sur le ressort des possibles du récit, brandissant constamment la menace du "morceau à faire", que ce soit un manifeste, une dissertation ou un récit de voyage, comme si le conte était le réceptacle privilégié d'une variété générique. Le conte, là encore, s'ouvre sur des récits virtuels, sur un texte infini; il sort de ses cadres et acquiert une puissance d'engendrement, une capacité de germination un peu folle. (Jomand-Baudry, 2002: 92-93)

\footnotetext{
${ }^{8}$ Cf. Jomand-Baudry (2002).
} 
Contra semelhante loucura insurge-se impacientemente a sultana: "Quel Conte! quel maussade Conte! quel indigne Conte! [...]. Des Dindons jouer de la flûte! Passe encore pour parler: on en entend quelques-uns dans le monde" (Crébillon, 2001: 408). Mais adiante, ela retorque ainda ao sultão, que defende a bizarria do conto:

Je n'ignore pas que le merveilleux le plus outré, les exagérations les plus puériles, les métamorphoses les plus absurdes, sont de l'essence du Conte; mais je sais aussi que, quelque bizarrerie qu'on lui permette, il faut, au moins, que les objets qu'il présente aient quelque chose d'agréable, et de piquant. II n'y a rien qui n'ait ses règles; et cette misère que l'on appelle un Conte, a les siennes, comme toute autre chose. (Crébillon, 2001: 408)

Parecendo defender as regras convencionadas e condenar os excessos inventivos, Crébillon está, pelo contrário, a antecipar acusações, por um lado e, por outro, a sugerir que, para além do prazer proporcionado pela leitura das bizarras metamorfoses das personagens encenadas, o verdadeiro valor do seu conto consiste, justamente, na problematização dos códigos e na inovação, isto é, numa metamorfose deste género literário, como já o fizera com a exclamação de Schah-Baham no final do Sopha: "Ah! Ma grand-mère! [...] ce n'était pas ainsi que vous contiez!" (Crébillon, 2000: 459). O sultão, tal como o leitor superficial, volta a revelar-se incapaz de fugir ao sortilégio dos contos maravilhosos, confundindo as fantasias pueris e frívolas de Moslem com acontecimentos grandiosos, sérios e inesperados (Crébillon, 2001: 453). A instância autoral, ao atribuir a esta personagem uma depreciação simulada e paródica do seu texto, reforça o convite sugerido ao longo da narrativa para que o leitor ultrapasse o nível do prazer da história e atinja um nível mais profundo de sentidos velados de crítica sentimental, social, política, filosófica e literária. O leitor é convidado ainda, como em todas as obras de Crébillon, a fruir do prazer de um discurso literário ousado e inovador.

Em conclusão, em Crébillon coexistem duas entidades, a do contista e a do moralista. Enquanto contista, o autor dá largas à sua imaginação, recuperando e transformando um vasto fundo cultural onde se cruzam as diferentes tradições associadas ao maravilhoso, nomeadamente no que respeita ao processo da metamorfose (e também da metempsicose). Nas quatro narrativas aqui tratadas, Le Sylphe, L'Écumoire, Le Sopha e Ah Quel Conte!, os sentidos da metamorfose correspondem, por um lado, a um processo estético-literário problematizador do exotismo maravilhoso na literatura setecentista; por outro, contudo, o processo metamórfico proporciona ao autor um meio lúdico e transgressor de criticar a moral e os costumes, pondo a nu o hedonismo e o culto da volúpia reinantes no seu tempo, assim como as manobras do poder político. Metamorfoses, encantamentos, 
filtros mágicos, metempsicose e demais parafrenália feérica, presentes nestas narrativas de aparência maravilhosa, estão, assim, ao serviço de uma visão crítica sobre a literatura e a sociedade coevas que caracteriza a poética deste escritor.

\section{Bibliografia}

Carvalho, Ana Alexandra Seabra de (2003). O Jogo do desejo em Claude Crébillon. Estudo dos processos retóricos da sedução. Lisboa: Fundação Calouste Gulbenkian / FCT.

(2011). "(In)verosímil e fantástico ou a arte de provocar o medo". In: Carnets III, L'(In)vraisemblable, janvier 2011, pp. 71-97. <URL: http://carnets.web.ua.pt >.

CAZENOBE, Colette (1991). Le système du libertinage de Crébillon à Laclos. Oxford: The Voltaire Foundation.

(1997). Crébillon fils ou la politique dans le boudoir. Paris-Genève: Éd. Honoré Champion.

CREBILlon, Claude (1999a). "Le Sylphe, ou Songe de Madame de $\mathrm{R}^{\star \star *}$ écrit par elle-même à Madame de $\mathrm{S}^{* * *}$ ". In: Jean Sgard (dir.). CEuvres complètes. Paris: Classiques Garnier Multimédia, t. I, pp. 23-37 (ed. crítica do texto: Carmen Ramirez).

(1999b). "Tanzaï et Néadarné, histoire japonaise". In: Jean Sgard (dir.). CEuvres complètes. Paris: Classiques Garnier Multimédia, t. I, pp. 269-439 (ed. crítica do texto: Jean Sgard).

(2000). "Le Sopha, conte morale". In: Jean Sgard (dir.) CEuvres complètes. Paris:

Classiques Garnier Multimédia, t. II, pp. 281-459 (ed. crítica do texto: Jean Sgard).

(2001). "Ah Quel Conte! Conte politique et astronomique”. In: Jean Sgard (dir.) CEuvres complètes. Paris: Classiques Garnier Multimédia, t. III, pp. 299-637 (ed. crítica do texto: Régine Jomand-Baudry).

JOMAND-BAUDRY, Régine (2001). "Introduction”. In: Claude Crébillon (2001). "Ah Quel Conte! Conte politique et astronomique". In: CEuvres complètes. Op. cit., t. III, pp. 273-297.

(2002). "La genèse de Ah quel conte! de Crébillon fils ou la fabrique du conte". In:

Régine Jomand-Baudry e Jean-François Perrin (orgs.). Le conte merveilleux au XVIIle siècle: Une poétique expérimentale. Paris: Éditions Kimé, pp. 87-101.

PERRIN, Jean-François (2002). "Petits traités de l'âme et du corps: les contes à métempsycose (XVIle-XVIIle siècles)". In: Régine Jomand-Baudry e Jean-François Perrin (orgs.). Le conte merveilleux au XVIIle siècle: Une poétique expérimentale. Op. cit., pp. 123139. 
RAmiReZ, Carmen (2002). "Le soupçon du merveilleux dans le conte des Lumières". In: Régine Jomand-Baudry e Jean-François Perrin (orgs.). Le conte merveilleux au XVIIle siècle: Une poétique expérimentale. Op. cit., pp. 212-228.

REY, Alain (dir.) (1992). Dictionnaire historique de la langue française. Paris: Dictionnaires Le Robert.

ROBERT, Raymonde (2002). "Le Canapé couleur de feu de Fougeret de Monbron et la veine 'gauloise' de la féerie”. In: Régine Jomand-Baudry e Jean-François Perrin (orgs.). Le conte merveilleux au XVIIle siècle: Une poétique expérimentale. Op. cit., pp. 229-242.

SGARD, Jean (1999). "Introduction". In: Claude Crébillon (1999b). "Tanzaï et Néadarné, histoire japonaise". In: QEuvres complètes. Op. cit., t. I, pp. 237-268.

(2002). "Allégorie d'une écumoire". In: Régine Jomand-Baudry e Jean-François Perrin (orgs.). Le conte merveilleux au XVIIle siècle: Une poétique expérimentale. Op. cit., pp. 140-148. 